\title{
METHOD VALIDATION AND STABILITY STUDY OF QUERCETIN IN TOPICAL EMULSIONS
}

Rúbia Casagrande*, Marcela M. Baracat e Sandra R. Georgetti

Departamento de Ciências Farmacêuticas, Centro de Ciências da Saúde, Universidade Estadual de Londrina, CP 6001, 86051-970

Londrina - PR, Brasil

Waldiceu A. Verri Jr

Departamento de Patologia, Centro de Ciências Biológicas, Universidade Estadual de Londrina, CP 6001, 86051-970 Londrina - PR, Brasil

Fabiana T. M. C. Vicentini, Janice A. Rafael, José R. Jabor e Maria J. V. Fonseca

Departamento de Ciências Farmacêuticas, Faculdade de Ciências Farmacêuticas de Ribeirão Preto, Universidade de São Paulo, Av. do Café, s/n, 14040-903 Ribeirão Preto - SP, Brasil

Recebido em 7/8/08; aceito em 11/3/09; publicado na web em 4/8/09

\begin{abstract}
This study validated a high performance liquid chromatography (HPLC) method for the quantitative evaluation of quercetin in topical emulsions. The method was linear within $0.05-200 \mu \mathrm{g} / \mathrm{mL}$ range with a correlation coefficient of 0.9997 , and without interference in the quercetin peak. The detection and quantitation limits were 18 and $29 \mathrm{ng} / \mathrm{mL}$, respectively. The intra- and inter-assay precisions presented R.S.D. values lower than $2 \%$. An average of $93 \%$ and $94 \%$ of quercetin was recovered for non-ionic and anionic emulsions, respectively. The raw material and anionic emulsion, but not non-ionic emulsion, were stable in all storage conditions for one year. The method reported is a fast and reliable HPLC technique useful for quercetin determination in topical emulsions.
\end{abstract}

Keywords: quercetin; HPLC; validation.

\section{INTRODUCTION}

Reactive oxygen species (ROS) including free radicals such as superoxide anion radicals $\left(\mathrm{O}_{2}^{-*}\right)$, hydroxyl radical species $\left({ }^{\circ} \mathrm{OH}\right)$, and hydrogen peroxide $\left(\mathrm{H}_{2} \mathrm{O}_{2}\right)$ are active oxygen compounds often generated by biological oxidative reactions, and induced by exogenous factors ${ }^{1}$ such as excessive sun exposure and increased air pollution.

In this context, antioxidants from natural products provide novel perspectives for the treatment and prevention of oxidative stress-mediated skin diseases by inhibiting or scavenging free radicals. ${ }^{2,3}$ Researches have been focused on the potential use of these drugs as free radical scavengers, especially for topical application to prevent oxidative skin damages. ${ }^{4,5}$ Quercetin is one of the major flavonoids found in foods like onions, apples, and teas. Its use in topical emulsion reduces UVB-induced oxidative and inflammatory skin damages. ${ }^{6}$

High performance liquid chromatography (HPLC) is a useful tool to analyze samples of complex nature like ointments and creams, because it provides not only the separation and determination, but also eliminates most interference problems. ${ }^{7}$ The first demonstration of the applicability of HPLC to determine flavonoids was in $1976,{ }^{8}$ and since then, several studies have described the validation of HPLC methods for quantifying flavonoids. However, most of them focused on their separation in food, medicinal plants or biological fluids. For instance, a validated HPLC method was used to separate and quantify three main flavonoids from the plant Achyrocline satureioides. ${ }^{9}$ Demonstration of HPLC assays to separate and quantify flavonoids aglycones from typical foods, ${ }^{8}$ as well as, to detect flavonoids in orange juice have also been reported. ${ }^{10}$

The aim of the present study was to validate an isocratic HPLC method for the determination of quercetin in topical emulsions as well as to evaluate physico-chemical stability of two proposed formulations, a nonionic one and another anionic.

*e-mail: rubiacasa@yahoo.com.br

\section{EXPERIMENTAL}

\section{Materials}

Quercetin was obtained from Acros (New Jersey, USA) and used as standard. Raw materials for formulations were obtained from Galena (Campinas, SP, Brazil). All other reagents used were pharmaceutical or chromatographic grade.

\section{Formulations}

A non-ionic emulsion (formulation 1) was prepared with commercially available self-emulsifying wax $\left(10 \%\right.$, Polawax ${ }^{\circledR}$ - cetostearyl alcohol and polyoxyethylene derived of a fatty acid ester of sorbitan 20E); and an anionic emulsion (formulation 2) was prepared with Polawax $^{\circledR}(2 \%)$, an anionic hydrophilic colloid $(0.18 \%$, carboxypolymethylene, Carbopol ${ }^{\circledR} 940$ ) served as a stabilizing agent and triethanolamine $(0.2 \%)$ as neutralizant. Macadamia nut oil $(2.5 \%)$ and squalene $(1 \%)$ were added as emollients, and propyleneglycol $(6 \%)$ as a moisturizer and solubilizer. The preservative used was a mixture of phenoxyethanol and parabens $\left(0.4 \%\right.$, Phenova $\left.{ }^{\circledR}\right)$. Deionized water was used to complete $100 \%(\mathrm{w} / \mathrm{w})$ in the preparation of all formulations. Quercetin ( $0.05 \%$ ) was solubilized in propyleneglycol and then added to the formulations at room temperature. Control formulations did not contain the flavonoid. All formulations were allowed to equilibrate for $24 \mathrm{~h}$ prior to use.

\section{Chromatographic conditions}

The chromatographic system consisted of a Shimadzu LC-10AT equipped with a $20 \mu \mathrm{L}$ loop and SPD-10A UV/VIS detector. Integration of the chromatographic peaks was achieved with C-R6A Chromatopac integrator (Shimadzu Corporation, Tokyo, Japan). Chromatography was performed on a Hypersil ${ }^{\circledR}$ BDS-CPS $C_{18}$ column $(5 \mu \mathrm{m} ; 250$ x $4.6 \mathrm{~mm}$ i.d.; Thermo Quest - Hypersil Division, Runcorn, UK) with a mobile 
phase of methanol: water (35:65; v/v) containing $2 \%$ acetic acid and flow rate of $1 \mathrm{~mL} / \mathrm{min}$. Each sample was prepared in triplicate. The volume injected was $20 \mu \mathrm{L}$ with detection at $254 \mathrm{~nm} .{ }^{11}$

\section{Preparation of standard solutions}

Standard quercetin was dissolved in methanol obtaining a solution of $1000 \mu \mathrm{g}$ of quercetin per $\mathrm{mL}$ of methanol. Then, this methanolic quercetin solution was diluted with mobile phase to yield the following concentrations: $0.05,0.5,1,2,5,10,25,50,100$ and $200 \mu \mathrm{g} / \mathrm{mL}$.

\section{Preparation of formulation samples}

Accurately weighed $0.5 \mathrm{~g}$ of formulations 1 and 2 containing the equivalent to $0.25 \mathrm{mg}$ of quercetin were transferred to $10 \mathrm{~mL}$ volumetric flasks which were completed with methanol. These solutions were 25 -fold diluted in mobile phase yielding solutions at the quercetin concentration of $1 \mu \mathrm{g} / \mathrm{mL}$. The same procedure was performed for control formulations 1 and 2 .

\section{Method validation}

The validation was performed based on the ICH Guidance,,$^{12}$ taking into account the parameters required for assaying dosage forms.

\section{Specificity}

The specificity of the method was evaluated by analyzing solutions of the control formulations 1 and 2. The samples were prepared as described in the preparation of formulation samples section, and analyzed as described in the chromatographic conditions. All analyses were performed in triplicate. The system response was examined through the presence of interference or overlaps with the quercetin formulations responses.

\section{Linearity}

For linearity experiments, solutions of quercetin were prepared at ten concentrations within the range of $0.05-200 \mu \mathrm{g} / \mathrm{mL}$ in 3 different days as described in the preparation of standard solutions section. The solutions were prepared in triplicate. The linearity was evaluated by linear regression analysis, which was calculated by the least square regression method.

\section{Limit of detection and limit of quantitation}

The limit of detection (LOD) and limit of quantitation (LOQ) parameters were determined on the basis of peak height and the slope of the regression equation. Analysis was performed in triplicate.

\section{Precision}

The precision of the assay was determined by repeatability (intraassay) and intermediate precision (inter-assay). Repeatability was evaluated by analysis of three determinations at different concentrations $(0.5,1$ and $2 \mu \mathrm{g} / \mathrm{mL}$, in triplicate), in the same day under the same experimental conditions. The intermediate precision was studied by assaying freshly prepared solutions of quercetin on three different days.

\section{Accuracy}

The accuracy experiments were performed applying the method to quantify quercetin in the presence of excipients of formulations. The control formulations were prepared as described in the preparation of formulation samples section, then, a known amount of quercetin $(10 \mu \mathrm{g} / \mathrm{mL})$ was added. Afterwards, samples were 10 fold diluted in mobile phase $(1 \mu \mathrm{g} / \mathrm{mL})$, filtered and analyzed. The results represent the mean of recovery for three independent samples.

\section{Physico-chemical stability evaluation}

Physico-chemical stability was evaluated by submitting the formulations to storage at $4{ }^{\circ} \mathrm{C}$, controlled room temperature (RT, $25^{\circ} \mathrm{C}$ ), $37{ }^{\circ} \mathrm{C}$, and $45^{\circ} \mathrm{C}$ during 365 days. ${ }^{13}$ Samples were collected at pre-determined time intervals for $\mathrm{pH}$, centrifugation, optical microscopic analyses and evaluation of quercetin concentration.

To determine the $\mathrm{pH}$, formulations were diluted 1:10 in deionized water and the analysis was performed in a Digmed $\mathrm{pH}$ meter apparatus. For the centrifugation assay, samples of the formulations were centrifuged at $3000 \mathrm{rpm}$ for $30 \mathrm{~min}$ at room temperature. Phase separation was visually analyzed, and globule size was evaluated using a Leica DMLB microscope equipped with a Leica DC 300 camera. ${ }^{14}$

To determine the quercetin concentration, the raw material was dissolved in methanol $(1000 \mu \mathrm{g} / \mathrm{mL})$ and diluted 1000 fold in the mobile phase to obtain a concentration of $1 \mu \mathrm{g}$ of quercetin per $\mathrm{mL}$. The same dilution procedure was performed for the formulations with quercetin and control formulations, i.e. first dilution in methanol and thereafter in mobile phase, obtaining the same concentration of quercetin $(1 \mu \mathrm{g} / \mathrm{mL})$ used in the analysis of raw material. All measurements were performed in triplicate.

\section{Statistical analysis}

Data were statistically analyzed by one-way ANOVA, followed by Bonferroni's multiple comparisons $t$-test for evaluation of storage conditions influence in the globule size of formulations 1 and 2. Results were presented as mean \pm SEM (standard error of the mean) and considered significantly different when $P<0.05$ was obtained.

\section{RESULTS AND DISCUSSION}

Topical administration of antioxidants is an efficient way to enrich the endogenous cutaneous system of protection, and thus, a successful strategy to decrease oxidative damage of the skin by ultraviolet irradiation. ${ }^{15}$ Quercetin is a promising compound to combat free radical diseases such as cancer and inflammatory conditions. Furthermore, its topical effectiveness to protect the skin from oxidative stress has been recently demonstrated, ${ }^{6,13,16}$ which reinforces the importance of quality control of topical formulation containing quercetin. In this sense, this work demonstrates one of the most valuable tools in the pharmaceutical analysis of quality control, ${ }^{11}$ which is a HPLC assay for the analysis of quercetin in topical formulations.

Firstly, analytical experiments addressed whether the excipients of formulations would interfere over quercetin quantification since emulsions are made of lipidic and aqueous components. The specificity was carried out through the comparison of the peak retention time of the formulations with quercetin and control formulations. No interference of the emulsion excipients was detected since no peak was detected in the same retention time of quercetin (Figures $1 \mathrm{~A}, \mathrm{~B}, \mathrm{C}$ and D). In the employed chromatographic conditions, quercetin presented a retention time of approximately 8.9 minutes for formulations 1 and 2, thus, allowing a rapid determination of the drug that is essential for routine analysis. ${ }^{17}$ Further confirming no interference of emulsion excipients, Figure $1 \mathrm{E}$ shows the chromatogram of standard quercetin presenting the same retention time as detected in Figures $1 \mathrm{~B}$ and D. 

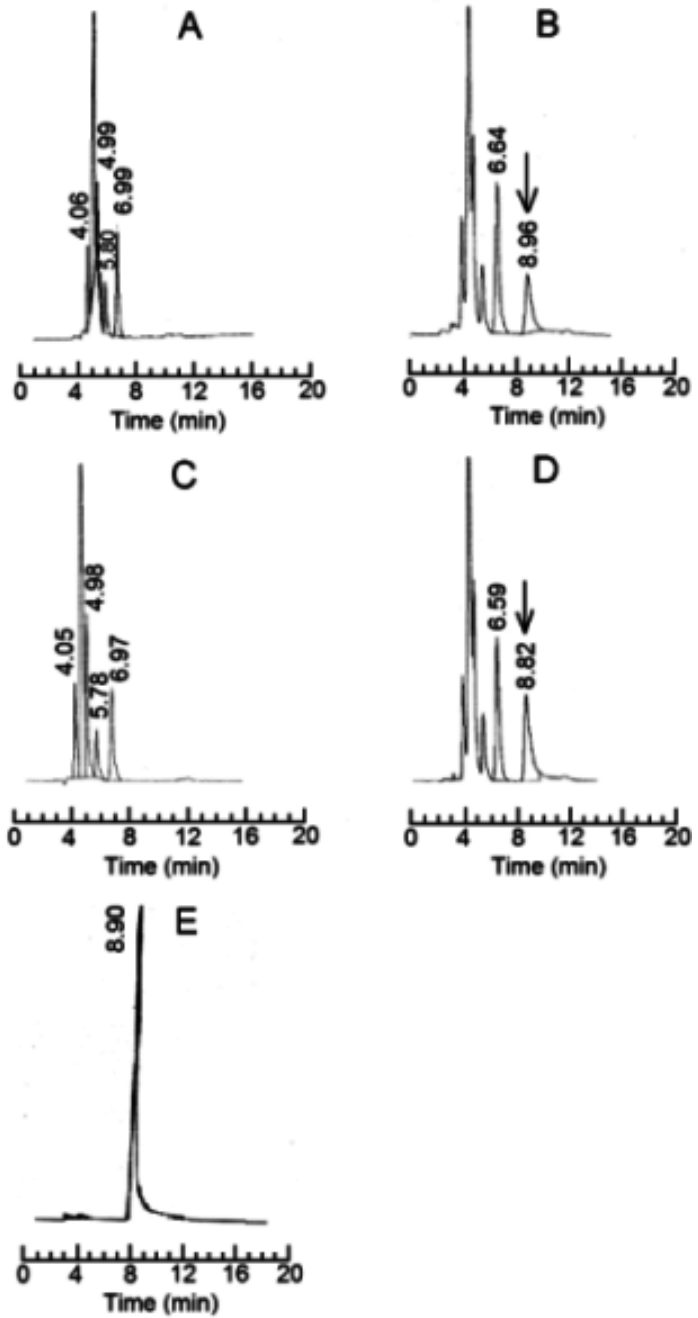

Figure 1. Chromatograms of control formulation 1 (A) and formulation 1 with quercetin $(B)$, control formulation $2(C)$ and formulation 2 with quercetin $(D)$ and standard quercetin (E). Chromatographic conditions: Hypersil ${ }^{\circledR} B D S-C P S$ $C_{18}$ column, $250 \times 4.6 \mathrm{~mm}$ attached to a pre-column, mobile phase: methanol: water $(35: 65 ; \mathrm{v} / \mathrm{v})$ containing $2 \%$ acetic acid, $1 \mathrm{~mL} / \mathrm{min}$

Analytical curves for quercetin were fitted by plotting concentration versus the corresponding mean peak height. Satisfactory linearity was detected in the $0.05-200 \mu \mathrm{g} / \mathrm{mL}$ range. The representative linear equation was $y=4022.5 x-265.43$, with a highly significant correlation coefficient $(r=0.9997)$ for the method. The detection and quantitation limits were calculated based on the standard deviation of the peak height and the slopes of the calibration curves. The values were found to be $18 \pm 0.53$ and $29 \pm 0.97 \mathrm{ng} / \mathrm{mL}$, respectively, indicating the high sensitivity of the method. ${ }^{17}$
The precision of the method was determined by repeatability (intra-assay) and intermediate precision (inter-assay), and shown as the relative standard deviation (R.S.D) in Table 1. The intra- and inter-assay precisions presented R.S.D. values lower than $2 \%$, which were satisfactory for the purpose of the analysis. ${ }^{12}$ The accuracy of the method was determined and the mean recoveries were 93 and $94 \%$ for formulations 1 and 2, respectively.

Table 1. Intra-assay and inter-assay precision for HPLC determination of quercetin

\begin{tabular}{lcc}
\hline \multicolumn{2}{c}{ Precision } \\
Conc. $(\mu \mathrm{g} / \mathrm{mL})$ & Intra-assay & Inter-assay \\
\hline & $(\mathrm{RSD})^{\mathrm{a}}$ & $(\mathrm{RSD})$ \\
0.5 & $0.56-1.23$ & 0.96 \\
1.0 & $0.042-1.47$ & 1.51 \\
2.0 & $0.79-1.51$ & 0.67 \\
\hline
\end{tabular}

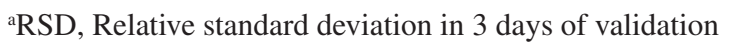

The stability evaluation of formulation's active principle stored at different climatic conditions for given times constitutes an important step for the development of novel products. It provides information concerning to the shelf-life of pharmaceutical products and conditions for their storage. ${ }^{13,18}$ Emulsions must be tested at widely varying temperatures in order to ensure that the product will remain stable throughout all possible conditions. For accelerated temperature testing, it is important to remember that temperature stability protocols depend on product category. Studies may range from freezing to very high temperatures and/or cycling between various temperatures. Generally, emulsions are stored at $-10{ }^{\circ} \mathrm{C}$ or $4{ }^{\circ} \mathrm{C}$, RT, $37{ }^{\circ} \mathrm{C}$, and $45^{\circ} \mathrm{C}$ or $50{ }^{\circ} \mathrm{C} . .^{13,18}$

Table 2 shows the initial observations obtained for $\mathrm{pH}$ values, centrifugation and globule size for formulations containing or not quercetin. It is necessary to control the $\mathrm{pH}$ of formulations since it must remain compatible with the components of formulation and with the application site, thus, avoiding irritation. ${ }^{14}$ During the one year-period of study, the formulations 1 and 2 showed a $\mathrm{pH}$ range of 5.10-5.40 and 6.84-7.16, respectively, which are compatible with topical use (Table 2).

The centrifugation test is of major interest since it provides fast information about comparable stability properties of different emulsions. It is consensus that physical stability of emulsions under normal storage conditions is rapidly predictable by observing the separation of the dispersed phase due to either creaming or coalescence when the emulsion is centrifuged. This test is specially employed to evaluate emulsions stability during pre-formulation stage, thus, can be useful to detect alterations during storage. ${ }^{14}$ Formulations 1 and 2 were stable since there was no separation of phases (Table 2).

Table 2. Influence of 1 year of storage at $45^{\circ} \mathrm{C}$ on the physico-chemical stability of topical formulations containing or not quercetin

\begin{tabular}{|c|c|c|c|c|c|c|}
\hline \multirow[t]{2}{*}{ Formulation } & \multicolumn{2}{|c|}{$\mathrm{pH}$} & \multicolumn{2}{|c|}{ Centrifugation } & \multicolumn{2}{|c|}{ Globule size $\left(\mu \mathrm{m}^{2}\right)$} \\
\hline & Initial & 1 year & Initial & 1 year & Initial & 1 year \\
\hline Control formulation 1 & 5.20 & 5.10 & NS & NS & $12.31 \pm 1.77$ & $10.59 \pm 2.40$ \\
\hline Formulation $1+$ quercetin & 5.40 & 5.32 & NS & NS & $11.18 \pm 2.32$ & $13.18 \pm 2.77$ \\
\hline Control formulation 2 & 7.01 & 6.84 & NS & NS & $18.45 \pm 3.97$ & $9.46 \pm 1.92$ \\
\hline Formulation $2+$ quercetin & 7.08 & 7.16 & NS & NS & $16.34 \pm 2.85$ & $9.56 \pm 2.20$ \\
\hline
\end{tabular}

NS: no separation. No statistical significant differences were detected in the globule size. 
The measurement of the globules size initially and during storage also provides an indication of the stability of the system, because the globules size increase indicates instability of the system. Several methods can be employed to measure globule size, being optical microscopy a common way of measuring the size of emulsion globules. ${ }^{14}$ Table 2 shows, as an example, the initial globule size and after one year of storage at $45^{\circ} \mathrm{C}$. Other storage conditions are not shown since there were no statistical differences between initial and one yearperiod storage at all temperatures tested. Smaller globules size were detected in formulation 1 compared to formulation 2 (Table 2). This is probably due to the higher content of surfactants in formulation 1. However, it seems that the globules size was not a major determinant and/or did not influence the quercetin stability since there was no modification in the globule size during the storage period.

The determination of quercetin content was used to evaluate the stability of the raw material and formulations over different conditions as shown in Figure 2. The raw material remained stable in all conditions during one year of storage. The major loss of initial quercetin content after one year was $48 \%$ for formulation 1 and $8 \%$ for formulation 2 at $45^{\circ} \mathrm{C}$. Therefore, in order to guarantee stability during shelf-life of formulation 1 , it is recommended to avoid excessive heat $\left(45^{\circ} \mathrm{C}\right)$ or refrigeration exposure for prolonged periods. A safer action is to predict $50 \%$ less time for stability in case formulation 1 is not properly stored, thus, a 180 day-shelf-life period.

Concluding, the present work reports a fast and reliable HPLC technique useful for routine quality control for quercetin determination in topical formulations.

\section{ACKNOWLEDGEMENT}

This work was supported by grants from Fundação de Amparo à Pesquisa do Estado de São Paulo (FAPESP) and Coordenação de Aperfeiçoamento de Pessoal de Nível Superior (CAPES).

\section{REFERENCES}

1. Halliwell, B.; Gutteridge, J. M. C.; Method Enzymol. 1990, 186, 1.

2. Aquino, R.; Morelli, S.; Tomaino, A.; Pellegrino, M.; Saija, A.; Grumetto, L.; Puglia, C.; Ventura, D.; Bonina, F.; J. Ethnopharmacol. 2002, 79, 183

3. Röpke, C. D.; Kaneko, T. M.; Rodrigues, R. M.; Silva, V. V.; Barros, S.; Sawada, T. C. H.; Kato, M. J.; Barros, S. B. M.; Int. J. Pharm. 2002, $249,109$.

4. Schoemaker, J. H.; Schoemaker, M. T.; Zijlstra, H.; van der Horst, F. A.; Dermatology 1995, 191, 36.

5. Mortimer, P. S.; Angiology 1997, 48, 87.

6. Casagrande, R.; Georgetti, S. R.; Verri, W. A., Jr; Dorta, D. J.; Santos, A. C.; Fonseca, M. J. V.; J. Photochem. Photobiol., B 2006, 84, 21.

7. Garcia, C. V.; Breier, A. R.; Steppe, M.; Schapoval, E. E. S.; Opper, T. P.; J. Pharm. Biomed. Anal. 2003, 31, 597.

8. Merken, H. M.; Beecher, G. R.; J. Agric. Food Chem. 2000, 48, 577.

9. De Souza, K. C. B.; Schapoval, E. E. S.; Bassani, V. L.; J. Pharm. Biomed. Anal. 2002, 28, 771.

10. Careri, M.; Elviri, L.; Mangia, A.; Musci, M.; J. Chromatogr., A 2000, $881,449$.

11. Saija, A.; Tomaino, A.; Trombetta, D.; Giacchi, M.; Pasquale, A. D.; Bonina, F.; Int. J. Pharm. 1998, 175, 85.

12. ICH steering committee international conference on harmonization of
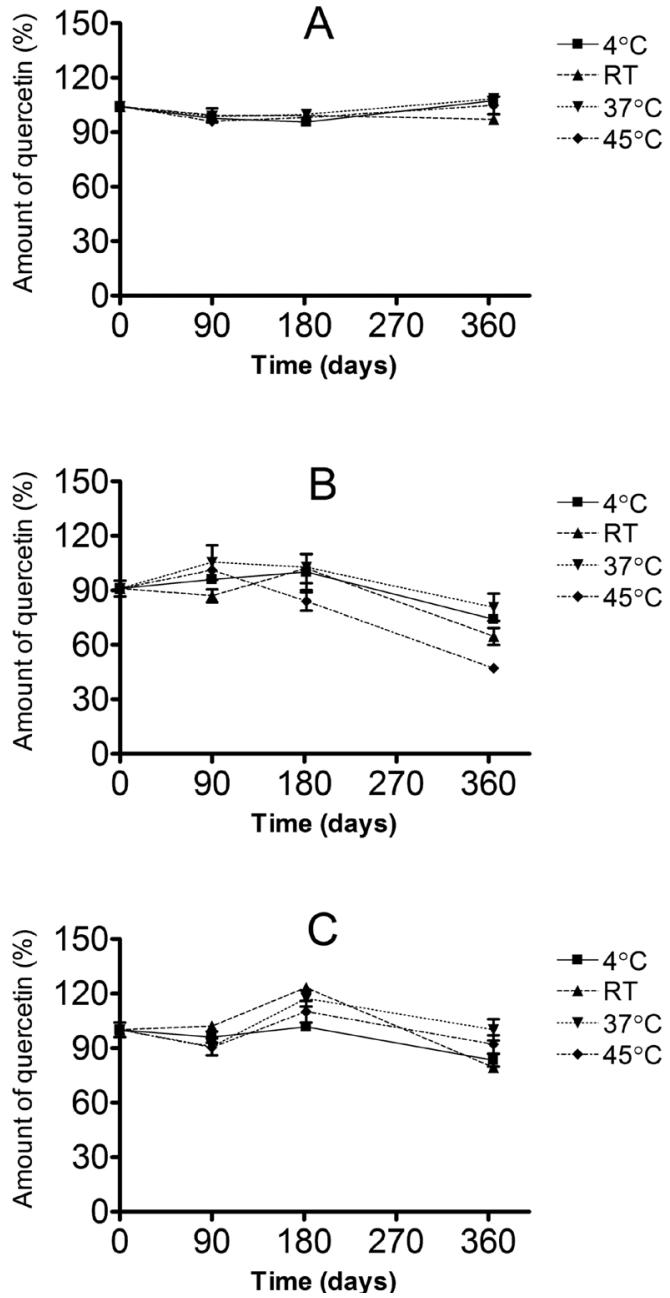

Figure 2. Percentage of quercetin found in raw material (A), formulations 1 (B) and 2 (C) following storage at $4{ }^{\circ} \mathrm{C}, \mathrm{RT}\left(25^{\circ} \mathrm{C}\right), 37^{\circ} \mathrm{C}$ and $45^{\circ} \mathrm{C}$ for 365 days. The initial concentration of quercetin was $1 \mu \mathrm{g} / \mathrm{mL}$ for raw material, formulation 1 and formulation 2 solutions. Results are represented by mean \pm standard error of the mean (SEM)

technical requirements for registration of pharmaceuticals for human use, validation of analytical procedures: text and methodology, Geneva, 2005, p. 13.

13. Casagrande, R.; Georgetti, S. R.; Verri, W. A., Jr; Jabor, J. R.; Santos, A. C.; Fonseca, M. J. V.; AAPS PharmSci Tech. 2006, 7, E1.

14. Georgetti, S. R.; Casagrande, R.; Vicentini, F. T. M. C.; Verri, W. A., Jr; Fonseca, M. J. V.; Eur. J. Pharm. Biopharm. 2006, 64, 99.

15. Montenegro, L.; Bonina, F.; Rigano, L.; Giogilli, S.; Sirigu, S.; Int. J. Cosmet. Sci. 1995, 17, 91.

16. Vicentini, F. T.; Simi, T. R.; Del-Ciampo, J. O.; Wolga, N. O.; Iyomasa, M. M.; Bentley, M. V.; Fonseca, M. J.; Eur. J. Pharm. Biopharm. 2008, 69, 948.

17. Mendez, A. S. L.; Steppe, M.; Schapoval, E. E. S.; J. Pharm. Biomed. Anal. 2003, 33, 947.

18. Casagrande, R.; Georgetti, S. R.; Verri, W. A., Jr; Borrin, M. F.; Lopez, R. F. V.; Fonseca, M. J. V.; Int. J. Pharm. 2007, 328, 183. 